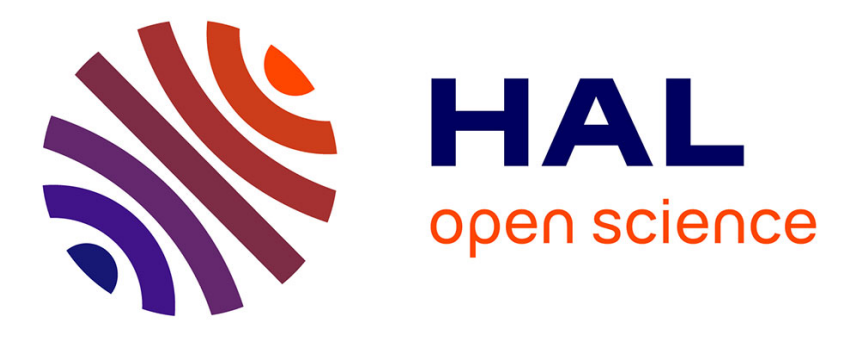

\title{
Fluoride etching opens the structure and strengthens the active sites of the layered ZSM-5 zeolite
}

\author{
Jan Přech, Krassimir Bozhilov, Jaafar El Fallah, Nicolas Barrier, Valentin
} Valtchev

\section{- To cite this version:}

Jan Přech, Krassimir Bozhilov, Jaafar El Fallah, Nicolas Barrier, Valentin Valtchev. Fluoride etching opens the structure and strengthens the active sites of the layered ZSM-5 zeolite. Microporous and Mesoporous Materials, 2019, Special Issue dedicated to the 65 birthday of Prof. Wieslaw J. Roth, 280, pp.297-305. 10.1016/j.micromeso.2019.02.023 . hal-02155088

\section{HAL Id: hal-02155088}

\section{https://hal-normandie-univ.archives-ouvertes.fr/hal-02155088}

Submitted on 22 Oct 2021

HAL is a multi-disciplinary open access archive for the deposit and dissemination of scientific research documents, whether they are published or not. The documents may come from teaching and research institutions in France or abroad, or from public or private research centers.
L'archive ouverte pluridisciplinaire HAL, est destinée au dépôt et à la diffusion de documents scientifiques de niveau recherche, publiés ou non, émanant des établissements d'enseignement et de recherche français ou étrangers, des laboratoires publics ou privés.

\section{(ㅇ)(1) $\$$}

Distributed under a Creative Commons Attribution - NonCommerciall 4.0 International 


\title{
Fluoride etching opens the structure and strengthens the active sites of the layered ZSM-5 zeolite
}

\author{
Jan Přech ${ }^{a}$, Krassimir N. Bozhilov $^{\mathrm{b}}$, Jaâfar El Fallah ${ }^{\mathrm{a}}$, Nicolas Barrier ${ }^{\mathrm{c}}$, Valentin Valtchev ${ }^{\mathrm{a}, *}$ \\ ${ }^{a}$ Normandie Univ., ENSICAEN, UNICAEN, CNRS, Laboratoire Catalyse et Spectrochimie, 14000 \\ Caen, France \\ ${ }^{\mathrm{b}}$ Central Facility for Advanced Microscopy and Microanalysis, University of California, Riverside, \\ CA 92521, USA \\ ${ }^{c}$ Normandie Univ., ENSICAEN, UNICAEN, CNRS, Laboratoire CRISMAT, 14050 Caen, France \\ ${ }^{*}$ Corresponding author, e-mail: valentin.valtchev@ensicaen.fr
}

\section{Abstract}

The $\mathrm{NH}_{4} \mathrm{~F}$ etching is a chemical approach for the preparation of hierarchical zeolites without substantial modification of their framework composition and acidic properties. We employed this approach to modify the 2-dimensional form of ZSM-5 and obtain a catalyst for bulky molecules conversion. The etching conditions were varied in order to obtain hierarchical ZSM-5 with different level of dissolution. Thus, obtained derivatives of 2-dimensional ZSM-5 were thoroughly studied in order to get deep insights into the effect of fluoride treatment. The 2-dimensional ZSM-5 was found unexpectedly stable under etching conditions, which is a consequence of the high quality of zeolite crystals containing a limited number of defect zones and misoriented crystalline domains, in contrast to conventional ZSM-5. Fluoride etching was also used to de-pillar 2-dimensional ZSM-5. The morphology and textural properties of the de-pillared ZSM-5 were very similar to those of the parent layered ZSM-5. Accordingly, amorphous and extra-framework species were dissolved first, resulting in the complete removal of 
extra-framework Al, thereby strengthening the active sites. In summary, the fluoride etching opens the structure of layered ZSM-5 and strengthens its acid sites when combined with dealumination during calcination.

\section{Keywords}

Fluoride etching, layered ZSM-5, hierarchical zeolite, acidity, de-pillaring

\section{Introduction}

Zeolites are of the most important industrial heterogeneous catalysts since their introduction into oil refining and petrochemistry in the 1960s. In addition, they are used as adsorbents and ion-exchangers thanks to their unique microporous structure, which provides, on one hand, high surface area and, on the other hand, shape selectivity and molecular sieving effects [1]. Although crude oil will most likely remain the main feedstock for transportation fuel and higher value chemicals in the next decades, research focus is currently shifting towards the processing of natural gas and bio-renewable carbon feedstocks. Accordingly, diverse and complex feedstocks will be used in the future and therefore new catalysts must be developed and tailored to meet new environmental and societal demands [2].

However, zeolite catalysts pose diffusional problems because their sub-nanometric channels prevent the diffusion or entry of bulkier molecules.

Notwithstanding, several approaches can be used to facilitate molecular transport within zeolite crystals. The size of zeolite crystals can be reduced to several tens of nanometres, thereby preparing nanozeolites [3, 4]; additional mesopores can be generated in zeolite crystals, which serve as molecular highways, rendering hierarchical zeolites [5]; alternatively, just one of the zeolite crystal dimensions can be reduced to a unit cell level, thus generating 2-dimensional, lamellar or layered zeolites [6]. The first two approaches can be applied, in principle, to all known zeolites, while 2-dimensional forms have been reported only for approximately $10 \%$ of known zeolites. Nevertheless, lamellar zeolites enable layer 
manipulations and other post-synthesis transformations, which can lead to more open structures; i.e., pillared zeolites [7], interlamellar-expanded zeolites [8, 9] or delaminated zeolites [10, 11], in some cases even with a house-of-cards morphology. Furthermore, additional active sites can be introduced between layers [12], or the layers can be reconnected into a different, fully connected zeolite (in the ADOR process [13]).

To synthesize layered zeolites, three different approaches are used [6]. (i) Some zeolites are formed via 2-dimensional zeolite precursors (e.g. MWW, FER). (ii) Zeolites containing chemical weaknesses in some positions can be disassembled using top-down protocol into a lamellar crystalline material (e.g., UTL, UOV, IWR, IWW). (iii) Some zeolites (e.g., MFI, MTV) can be prepared in a lamellar form using a restricted crystal growth mechanism, when a surfactant template is used to block crystal growth in one of the crystallographic directions, thus generating discrete crystals in the form of nanosheets [14].

The aforementioned hierarchical zeolites can be prepared using several bottom-up and top-down approaches. The most commonly used bottom-up approaches are hard templating, polymer templating and organosilane-based synthesis. Conversely, top-down approaches include chemical etching, such as desilication, dealumination and degermanation. All these approaches are based on the selective extraction of framework cations. Recently, a fluoride etching approach to hierarchical zeolites with retained framework composition was discovered $[15,16]$. The great advantage of this approach is the similar rate of extraction of different framework cations. Therefore, this method has no effect on the chemical composition and acidic properties. Another advantage is the preferential extraction of defect zones in the crystals, which are more vulnerable to chemical attack [15]. Initially, etching starts from the boundaries of intergrown crystals, thus separating twins into single crystals [17]. Under specific conditions, the fluoride etching of zeolite ZSM-5 (MFI), e.g., provides a material with small rectangular 
mesopores due to the extraction of misoriented nanocrystalline domains, thereby resulting in a single crystal, sponge-like morphology [16].

Considering the impact of fluoride etching on conventional zeolite ZSM-5, we aimed to investigate the effect of fluoride etching of layered forms of the ZSM- 5 zeolite for layered ZSM-5 delamination. Herein, we report the ammonium fluoride etching of as-synthesized layered, calcined-layered and pillared ZSM5 zeolites and the detailed physicochemical characterisation of the resulting materials. Moreover, pillared ZSM-5 was de-pillared, that is, pillared ZSM-5 was transformed back into layered ZSM-5, similar to the zeolite formed by simple calcination of a parent as-synthesized zeolite. To our best knowledge, this is the first study on the fluoride etching of a 2-dimensional zeolite.

\section{Experimental}

\subsection{Preparation of parent materials}

Parent layered ZSM-5 (denoted lamZSM-5-(30)), where 30 is the Si/Al ratio, was synthesized following the procedure reported in [14]. Briefly, $46.4 \mathrm{~g}$ of distilled water was combined with $2.060 \mathrm{~g}$ of $\mathrm{NaOH}$ (98\%, VWR Chemicals), $0.948 \mathrm{~g}$ of $\mathrm{Al}_{2}\left(\mathrm{SO}_{4}\right)_{3} \cdot 18 \mathrm{H}_{2} \mathrm{O}$ (98\%, Sigma Aldrich) and $1.367 \mathrm{~g}$ of $\mathrm{H}_{2} \mathrm{SO}_{4}$ (96\%, Sigma

Aldrich) under stirring. Each reagent was added after complete dissolution of the previous. Then, $17.88 \mathrm{~g}$ of tetraethyl orthosilicate (TEOS, 98\%, Sigma Aldrich) was introduced and hydrolysed under stirring at room temperature for $1 \mathrm{~h}$. Subsequently, $6.00 \mathrm{~g}$ of surfactant structure directing agent (SDA) $\mathrm{C}_{22} \mathrm{H}_{45}-\mathrm{N}^{+}-$ $\left(\mathrm{CH}_{3}\right)_{2}-\mathrm{C}_{6} \mathrm{H}_{12}-\mathrm{N}^{+}-\left(\mathrm{CH}_{3}\right)_{2}-\mathrm{C}_{6} \mathrm{H}_{13} \mathrm{Br}_{2}$ was added, and the synthesis gel was homogenised for another $1 \mathrm{~h}$. The SDA was prepared following [14] and its structure and purity was confirmed using ${ }^{1} \mathrm{H}$ - and ${ }^{13} \mathrm{C}-\mathrm{NMR}$ spectroscopy (spectra not shown). The final gel had $\mathrm{pH}=11$ and the following molar composition: 60 $\mathrm{NaOH}: 1.66 \mathrm{Al}_{2}\left(\mathrm{SO}_{4}\right)_{3}: 16 \mathrm{H}_{2} \mathrm{SO}_{4}: 100 \mathrm{SiO}_{2}: 10 \mathrm{SDA}: 3000 \mathrm{H}_{2} \mathrm{O}$. Hydrothermal synthesis of the lamellar ZSM-5 was performed in two Teflon-lined autoclaves under tumbling (40 rpm) at $160^{\circ} \mathrm{C}$ for $217 \mathrm{~h}$. After 
this period, the solid product was collected by filtration, washed with distilled water and dried at $30^{\circ} \mathrm{C}$, forming $7.50 \mathrm{~g}$ of lamZSM-5(30) in as-synthesized form.

A part of the lamZSM-5-(30) was calcined in an air-flow $(100 \mathrm{ml} / \mathrm{min})$ at $550^{\circ} \mathrm{C}$ for $8 \mathrm{~h}$ with a temperature ramp of $2^{\circ} \mathrm{C} / \mathrm{min}$. The calcined product, without further treatment, was subjected to $\mathrm{NH}_{4} \mathrm{~F}$ etching.

LamZSM-5-(35) was prepared similarly to the lamZSM-5-(30) but with a modified initial Si/Al molar ratio of 35 by decreasing the amount of $\mathrm{Al}_{2}\left(\mathrm{SO}_{4}\right)_{3} \cdot 18 \mathrm{H}_{2} \mathrm{O}$. Part of the material was calcined and ion-exchanged, as described above; the rest was subjected to pillaring [7]. Silica-pillared ZSM-5 was prepared according to the procedure reported in reference [20]. The as-synthesized layered ZSM-5 (35) was mixed with TEOS (10 ml/g of zeolite) and stirred at $85^{\circ} \mathrm{C}$ for $20 \mathrm{~h}$. Subsequently, the solid product was centrifuged, dried, hydrolysed in water at room temperature for $24 \mathrm{~h}$ and, after filtration and drying, finally calcined at $540^{\circ} \mathrm{C}$ for $6 \mathrm{~h}\left(\operatorname{ramp~} 2^{\circ} \mathrm{C} / \mathrm{min}\right)$.

For acidity analysis and catalytic testing, all samples were ion-exchanged into the $\mathrm{NH}_{4}{ }^{+}$form using a 1-M $\mathrm{NH}_{4} \mathrm{NO}_{3}$ solution four times ( $100 \mathrm{ml} / \mathrm{g}$ of zeolite, $4 \mathrm{~h}$ each time). Subsequently, the samples were converted into $\mathrm{H}^{+}$-form by calcination at $450^{\circ} \mathrm{C}$ for $2 \mathrm{~h}$.

\subsection{Fluoride etching}

The ammonium fluoride etching of the parent zeolites follows the procedures described in [16]. The following key parameters experimentally changed: (i) initial zeolite state: as-

synthesised/calcined/pillared; and (ii) etching time. Typically, a 40 wt.\% solution of $\mathrm{NH}_{4} \mathrm{~F}$ was prepared from $8.0 \mathrm{~g}$ of $\mathrm{NH}_{4} \mathrm{~F}$ (98\%, Sigma-Aldrich) and $12.0 \mathrm{~g}$ of distilled water. This etching solution was preheated to $50^{\circ} \mathrm{C}\left(+/-2^{\circ} \mathrm{C}\right)$ in a $40 \mathrm{kHz}$ ultrasonic bath, in a closed polypropylene bottle. The ultrasound was used to maintain good mixing and to promote crystal separation once the grain boundaries are etched. Subsequently, $1 \mathrm{~g}$ of the parent layered ZSM- 5 was added to the bottle, well shaken, and left in 
the ultrasonic bath for a specific time (shown in Table 1). The temperature of the bath was controlled by adding ice. The etching time was $13 \mathrm{~min}$ for the calcined layered ZSM-5 and up to $140 \mathrm{~min}$ for assynthetized layered ZSM-5. At the end, the suspension was quickly filtered on a Buchner funnel and washed several times with distilled water (approximately totalling $200 \mathrm{ml}$ ). The solid product was dried at $30^{\circ} \mathrm{C}$, calcined (if the sample was subjected to fluoride treatment before calcination), and characterised. Calcination conditions were the same as for parent lamZSM-5-(30). Exceptions are mentioned in the results and discussion section.

\subsection{Characterisation}

Powder X-ray diffraction (XRD) patterns were collected on a PANanalytical X'Pert PRO and a Bruker D8 Advance Vario 1 diffractometers both equipped with Johansson monochromators and using CuKa-1 radiation $(\lambda=0.15406 \mathrm{~nm})$. On the $X^{\prime}$ pert PRO diffractometer, data were collected in continuous mode in Bragg-Brentano geometry over the $2 \vartheta$ range of $3-40^{\circ}$ using a $14^{\circ}$ divergence slit. $A 1 / 32^{\circ}$ slit was used to observe low angle reflections $\left(2 \vartheta=1-10^{\circ}\right)$. On the D8 diffractometer, data were collected in DebyeScherrer geometry, on capillaries of $0.3 \mathrm{~mm}$ diameter over the $2 \vartheta$ range of $1-40^{\circ}$ using a $0.05 \mathrm{~mm}$ $\left(\sim 0.025^{\circ}\right)$ divergence slit.

Scanning electron microscopy (SEM) images were collected on a MIRA TESCAN microscope equipped with a field emission gun. The images were collected with an acceleration voltage of $30 \mathrm{kV}$. Samples were platinum sputtered before measurement.

Nitrogen sorption isotherms were measured at liquid nitrogen temperature $\left(-196^{\circ} \mathrm{C}\right)$ using a Micromeritics Triflex instrument. Samples were outgassed under turbomolecular pump vacuum at $300^{\circ} \mathrm{C}$ for $6 \mathrm{~h}$ before measurement. The BET area was evaluated using adsorption data in a relative pressure ranging from $\mathrm{p} / \mathrm{p}_{0}=1.1 .10^{-7}$ to $\mathrm{p} / \mathrm{p}_{0}=0.01$ (corresponding to the growing part of Rouquerol BET plot). The t-plot method [18] was applied to determine the external surface area $\left(\mathrm{S}_{\text {ext }}\right)$. Micropore volume 
$\left(V_{\text {mic }}\right)$ was determined from non-local DFT pore size analysis using a model for $\mathrm{N}_{2}$ on oxide surface with cylindrical geometry (part of the Micromeritics user software). The adsorbed amount of nitrogen at $p / p_{0}$ $=0.95$ was used to determine the total pore volume $\left(V_{\text {total }}\right)$.

Elemental analysis was performed using an ICP-OES method. Samples were dissolved in a mixture of HF and Aqua Regia before the analysis.

Infrared spectra were collected with a Thermo Scientific Nicolet 6700 FT-IR spectrometer at $4 \mathrm{~cm}^{-1}$ optical resolution by collecting 128 scans for a single spectrum. The individual samples were pressed into self-supporting wafers with a density of $8.0-12 \mathrm{mg} / \mathrm{cm}^{2}$ and activated at $450^{\circ} \mathrm{C}$ for $5 \mathrm{~h}$ with a temperature ramp $2^{\circ} \mathrm{C} / \mathrm{min}$ under vacuum of a turbomolecular pump (final pressure $1.0-1.510^{-6}$ torr). The strength and number of acid sites were determined from adsorption/desorption of pyridine (py). Pyridine adsorption was performed at $150^{\circ} \mathrm{C}$ for $30 \mathrm{~min}$, at a partial pressure of 1 torr, followed by sequential desorption at different temperatures $\left(150,250,350,450^{\circ} \mathrm{C}\right)$ to estimate the strength of the acid sites. Desorption at each temperature was performed under vacuum of a turbomolecular pump for $15 \mathrm{~min}$, which suffices to stabilise the amount of adsorbed pyridine. Spectra were recalculated to a wafer density of $10 \mathrm{mg} / \mathrm{cm}^{2}$. Concentrations of acid sites were determined after desorption at $150^{\circ} \mathrm{C}$ from integral intensities of bands at $1454 \mathrm{~cm}^{-1}$ (Lewis) and at $1545 \mathrm{~cm}^{-1}$ (Brønsted acid sites) using extinction coefficients, $\varepsilon(\mathrm{L})=1.28 \mathrm{~cm} / \mu \mathrm{mol}$, and $\varepsilon(B)=1.13 \mathrm{~cm} / \mu \mathrm{mol}[19]$.

${ }^{27} \mathrm{Al}-\mathrm{MAS}-\mathrm{NMR}$ spectra were collected on a Bruker Avance III HD $500 \mathrm{MHz}$ spectrometer. Chemical shifts were referred to $0.1 \mathrm{M} \mathrm{Al}\left(\mathrm{NO}_{3}\right)_{3}$ aqueous solution. All samples in $\mathrm{H}^{+}$form were hydrated in saturated water vapour at $25^{\circ} \mathrm{C}$ for $24 \mathrm{~h}$ and analysed at a sample spinning speed of $12 \mathrm{kHz}$. 


\subsection{Catalytic testing}

Prior to their loading into reactors, the catalysts were pre-activated in a dry air-flow $(100 \mathrm{ml} / \mathrm{min})$ at $450^{\circ} \mathrm{C}$ for $2 \mathrm{~h}$ (temperature ramp $5^{\circ} \mathrm{C} / \mathrm{min}$ ), removed from the oven at a temperature $>200^{\circ} \mathrm{C}$ and cooled down in a desiccator.

Isomerisation of $\mathrm{m}$-xylene $(\mathrm{p}=2.5 \mathrm{kPa})$ was performed in a Pyrex glass tubular fixed bed reactor $(\mathrm{ID}=7$ $\mathrm{mm}$ ) operating in a gas phase under atmospheric pressure at $350^{\circ} \mathrm{C}$. Hydrogen was used as a carrier gas. The catalyst bed consisted of $40 \mathrm{mg}$ of catalyst (200-500 $\mu \mathrm{m}$ particle size) mixed with $400 \mathrm{mg}$ of SiC (200$300 \mu \mathrm{m})$. To remove any traces of water, the catalytic bed was activated at $400^{\circ} \mathrm{C}$ for $1.5 \mathrm{~h}$ in a dry air flow $(50 \mathrm{ml} / \mathrm{min}$ ) and subsequently cooled to the reaction temperature, flushed with nitrogen and hydrogen, and the reactant saturated feed was finally introduced. The WHSV ranged from 7 to $15 \mathrm{~h}^{-1}$. The products were analysed with a Bruker 430 gas chromatograph equipped with a pneumatic sampling valve connected to the reactor outlet, Varian CP-ChiraSil Dex-CB capillary column $(25 \mathrm{~m} \times 0.25 \mathrm{~mm} \times$ $0.25 \mu \mathrm{m})$ and with a flame ionisation detector.

Dealkylation of 1,3,5-tri-isopropylbenzene (TiPBz, $p=167 \mathrm{~Pa}$ ) was performed in a stainless steel tubular fixed bed reactor $(I D=12.7 \mathrm{~mm})$ in gas phase under atmospheric pressure at $220^{\circ} \mathrm{C}$. Nitrogen was the carrier gas. In total, $20 \mathrm{mg}$ of the catalyst (particle size 200-500 $\mu \mathrm{m}$ ) was closed between two layers of inert SiC (particle size 200-300 $\mu \mathrm{m}$ ). To remove any traces of water, the catalytic bed was activated at $450^{\circ} \mathrm{C}$ for $2 \mathrm{~h}$ in a dry air flow $(50 \mathrm{ml} / \mathrm{min}$ ) and then cooled to the reaction temperature, flushed with nitrogen, and the reactant saturated feed was introduced (total flow $205 \mathrm{ml} / \mathrm{min}$ ). The WHSV was $8.5 \mathrm{~h}^{-1}$ and steady state was achieved within $2 \mathrm{~min}$. Therefore, the first sample was taken at T-O-S=2 min. The products were analysed with a Varian CP 3800 gas chromatograph equipped with a pneumatic sampling valve connected to the reactor outlet, HP-Pona capillary column ( $50 \mathrm{~m} \times 0.2 \mathrm{~mm} \times 0.5 \mu \mathrm{m}$ ), and with a flame ionisation detector. 


\section{Results and discussion}

In this study, layered as-synthesized, layered calcined and pillared ZSM-5 zeolites were etched in concentrated ammonium fluoride solutions in an ultrasonic bath. Details on $\mathrm{NH}_{4} \mathrm{~F}$ solution concentration, temperature and time are outlined in Table 1. Two levels of treatment with different intensities were used. Mild conditions were characterised by lower temperature (e.g. $33^{\circ} \mathrm{C}$ for lamZSM5-(30)-AC5), lower etching time and lower concentration of $\mathrm{NH}_{4} \mathrm{~F}$ (typical procedure includes using 20 wt.\% $\mathrm{NH}_{4} \mathrm{~F}$ solution). Harsh conditions (typically using $40 \mathrm{wt} . \% \mathrm{NH}_{4} \mathrm{~F}$ solution at $50^{\circ} \mathrm{C}$ ) were optimised to achieve approximately $50 \%$ weight loss of the material. For comparison, typical etching conditions for conventional ZSM-5 (Si/Al=21) are $40 \mathrm{wt} . \% \mathrm{NH}_{4} \mathrm{~F}$ solution at $50^{\circ} \mathrm{C}$ for $5-60 \mathrm{~min}$ [16] and $50 \%$ weight loss is achieved in approximately $30 \mathrm{~min}$. Samples denoted lamZSM-5-(30) and lamZSM-5-(35) are parent batches of layered ZSM-5 with Si/AI molar ratio 30 and 35, respectively. Samples denoted lamZSM-5(30)-BC** have been etched in the as-synthesized form (that is, with the surfactant template in their structure) and the number instead of ** reflects the etching time. An additional surfactant (10 wt.\%) was added in one case to promote layer separation; the sample is marked with a CTAB note. Samples denoted lamZSM-5-(30)-AC** and etching time ** have been etched after calcination. In general, zeolites containing template are more stable in the ammonium fluoride solution because fluoride ions cannot enter template-filled micropores. Therefore, the etching times were higher than those used in the calcined samples. The sample denoted pill-ZSM-5-(35) is pillared ZSM-5 in which individual layers are supported by amorphous silica pillars [20]. The pillars preserve the interlayer distance in the assynthesized sample, wherein layers are kept apart by the hydrophobic tails of the surfactant template $[14,22]$. The sample de-pill-ZSM-5-(35) was obtained by fluoride etching of the pill-ZSM-5-(35).

In the initial experiments, which were performed under mild conditions (represented by lamZSM-5-(30)$\mathrm{BC} 30$ and lamZSM-5-(30)-AC5), the materials were unexpectedly stable (as shown by their low weight loss (15\% resp. 13\%) and the retained morphology (Figure 1)). The layered ZSM-5 samples were 
expected to dissolve quickly, particularly the calcined sample, because the individual layers are of few unit cell thickness and even their aggregates, observed in the SEM (Figure 1), are only several tens of nm thick. However, this fast dissolution was not observed and therefore the treatment was intensified (lamZSM-5-(30)-BC140 resp. lamZSM-5-(30)-AC13).

Figure 2 presents the powder XRD patterns of the parent lamZSM-5-(30) sample and of the derived etched materials. All diffractograms contain Bragg peaks typical of the MFI structure. However, all of them are broad and $(h 0 /)$ lines are the most sharp. These features are characteristic of layered ZSM-5 materials due to the lack of a long-range order, particularly in the direction of crystallographic $b$-axis [14, 21,23 ]. Differences in the intensity of the XRD patterns may be attributed to the density of the sample in a holder rather than to the overall crystallinity (cf. SEM and TEM images in Figure 1, Figure 7). There are two additional lines the in XRD pattern of lamZSM-5-(30) as-synthesized at $2 \vartheta=4.2^{\circ}$ and $7.2^{\circ}$. The line at $4.2^{\circ}$ is a $3^{\text {rd }}$ order reflection belonging to the multilamellar stacking $(d=6.3 \mathrm{~nm}$ ) of nanosheets supported by the surfactant chains of the template [23], which shows that the material is layered. However, the origin of the weak $7.2^{\circ}$ reflection is unclear; it might be a (002) reflection of the nanolayered silicate phase, from which the layered ZSM-5 crystallise [24]; but this weak reflection did not disappear, even with prolonged crystallisation, and persisting even in the XRD pattern of lamZSM-5(30)-BC30 before calcination (not shown). Hence, the line at $7.2^{\circ}$ reflects a structural feature that survives fluoride etching. This line disappears after calcination (both lamZSM-5-(30) and lamZSM-5-(30)$\mathrm{BC} 30)$, together with the line at $2 \vartheta=4.2^{\circ}$.

Figure 3 presents the XRD patterns of the layered, pillared and de-pillared ZSM-5 (35). The patterns were measured with a $1 / 40^{\circ}$ divergence slit; therefore, the lines are sharper but less intense, despite the longer measurements. The high-angle region contains the same features as those described above. In the low-angle region, a shoulder is identified at approximately $2 \vartheta=1.3^{\circ}$. This is a $1^{\text {st }}$-order reflection of 
the interlayer $d$-spacing. This reflection is present only in the as-synthesized samples of lam ZSM-5, where the layers are supported by the surfactant templates and in pillared ZSM- 5 samples, wherein layers are supported by amorphous silica pillars and therefore the original interlayer distance of the assynthesized material remains unaltered. In contrast, when the surfactant template is removed by calcination or the silica pillars are removed by fluoride etching, the layers collapse onto each other, the interlayer distance decreases and they become less ordered, and this and the aforementioned low-angle reflection at $4.2^{\circ}$ disappear $[21,25]$.

All the lamZSM-5-(30) samples (parent and $\mathrm{NH}_{4} \mathrm{~F}$-etched) exhibit a nitrogen adsorption isotherms at $196^{\circ} \mathrm{C}$ typical of the multilamellar ZSM-5 $[14,26]$ and the etching did not result in a significant change of the isotherm character (Figure S 1, Figure S 2). The etching of lam ZSM-5 increased the external surface area (Table 2). The external surface area of the as-synthesized samples increased with the treatment harshness (from $86 \mathrm{~m}^{2} / \mathrm{g}$ via $92 \mathrm{~m}^{2} / \mathrm{g}$ after $30 \mathrm{~min}$ to $142 \mathrm{~m}^{2} / \mathrm{g}$ after $140 \mathrm{~min}$ treatment), while the external surface area of calcined samples showed no difference between the mild and harsh treatments. $\mathrm{CTABr}$ addition to the etching mixture (lamZSM-5-(30)-BC140-CTAB) slightly increased the total adsorption capacity and the external surface area, albeit causing no layer rearrangement. We even expected the formation of a house-of-cards morphology because breaking nanosheets into smaller pieces and subjecting the samples to ultrasound were expected to promote rearrangements. However, the changes observed in textural properties suggest that the house-of-cards structure was not formed.

When a conventional zeolite ZSM-5 is subjected to fluoride etching, the total pore volume and the external surface area gradually increase during etching as random parts of the structure are removed and thus mesopores are formed [16]. In contrast, the layered material already has a high total pore volume and removing parts of structure from the layered ZSM-5 causes no change in morphology. Therefore, the changes in textural properties, particularly in pore volume, are small. 
In contrast, the etching of pillared ZSM-5 is accompanied by significant changes. The pillaring of the layered ZSM-5 results in the preservation of the interlayer distance of the as-synthesized material, and thus, after calcination, small mesopores with a size corresponding to the interlayer distance are observed, gradually increasing the amount of nitrogen adsorbed in $\mathrm{p} / \mathrm{p}_{0}=0.1-0.4$ range (Figure 4). When a pillared ZSM-5 was subjected to etching, the pillars, consisting of amorphous silica, were dissolved first, subsequently forming a material with an isotherm and textural properties very similar to the parent lamellar ZSM-5. This de-pillaring is a conceptually important finding because it represents a new, layered zeolite transformation. The pillars can be selectively removed while preserving the crystalline layers. Moreover, this approach cleans a zeolitic phase to $100 \%$ crystallinity (evidenced e.g. by the ${ }^{27} \mathrm{Al}-\mathrm{MAS}-\mathrm{NMR}$, vide infra) by a post-synthesis treatment [16]. Figure 5 shows that the morphology of the material is preserved during both pillaring and de-pillaring operations.

We expected that fluoride etching could be used to delaminate ZSM-5, ultimately building a highly open house-of-cards structure. The etching (performed always in an ultrasonic bath) caused a small increase in the external surface area, which was augmented when adding a surfactant to the etching solution (vide supra), albeit with no expansion of the interlayer distance (Figure 6). Figure 7 shows TEM images of the parent and etched lamZSM-5-(30) from the top view of the layers (along the $b$-axis). Initially, the uniform nanosheets (Figure 7a) of the parent material exhibited slight damage upon mild treatment (lamZSM-5-(30)-BC30). However, upon harsh treatment, they adopted a flake-like morphology intermediate between a nanozeolite [3] and a layered zeolite. This morphology is formed while etching both calcined and as-synthetized zeolites (Figure 7c,d). Importantly, the materials preserved their macroscopic features, i.e., morphology and thus easy processability. In contrast to nanozeolites, the present materials can be, for instance, easily collected by filtration. Also, no changes in mechanical properties of the catalysts were observed during preparation of IR pellets. 
Ammonium fluoride etching of conventional zeolites is known to maintain the acidic properties and chemical composition of the resulting materials [16]. Thus, the acidic properties of etched layered ZSM5 were investigated by pyridine adsorption/desorption at various temperatures, the elemental composition was studied, and the amount of framework and extra-framework aluminium was analysed by ${ }^{27} \mathrm{Al}-\mathrm{MAS}-\mathrm{NMR}$. The concentration of Lewis and Brønsted acid sites after desorption at $150^{\circ} \mathrm{C}$ reflects the total concentration of acid sites, while desorption at $350^{\circ} \mathrm{C}$ reveals the concentration of strong acid sites (cf. Table 3, and ${ }^{27} \mathrm{Al}-\mathrm{NMR}$ spectra in Figure 8).

The ${ }^{27} \mathrm{Al}-\mathrm{NMR}$ spectra (Figure 8) of the lamZSM-5-(30) based samples show two main signals. The strong signal around $55 \mathrm{ppm}$ belongs to framework Al atoms with tetrahedral coordination, while the sharp peak at $0 \mathrm{ppm}$ belongs to octahedrally coordinated cationic $\mathrm{Al}^{3+}[27,28]$. Its intensity (after deconvolution) was used to quantify the relative amount of this species. After carefully analysing the spectra, we observed another broad signal between 10 and -35 ppm belonging to polynuclear extraframework Al clusters. The share of extra-framework Al was determined from the integral intensity of these signals between 10 and -35 ppm.

The spectrum of parent lamZSM-5-(30) and the spectra of samples etched before calcination contain all the above mentioned signals (Figure 8). In contrast, the spectrum of lamZSM-5-(30)-AC13 contains only the signal at $55 \mathrm{ppm}$, proving that this material contains no extra-framework Al. Note that the spectrum of parent lam ZSM-5 reflects the state before etching, which forms the lamZSM-5-(30)-AC13 sample; therefore, we analysed the changes in Al-NMR spectra caused directly and solely by fluoride etching, which explained the origin of the observed extra-framework Al. The layered ZSM- 5 contains up to 40 wt.\% of organic template and water before calcination ( $42 \%$ is a typical weight loss upon calcination). Thus, during calcination, the burning of the organic template provides conditions severe enough to cause partial dealumination of the zeolite $[29,30]$. Fluoride treatment preferentially washes out any 
species that are not an integral part of the zeolite framework. Therefore, the material treated after calcination exclusively contains the framework Al, while all others also contain the extraframework Al because they did not undergo the fluoride treatment (parent sample) or were subsequently exposed to the dealumination (steaming) conditions (samples etched in as-synthesized state). Note that only a weak broad signal between 10 and -35 ppm is detected in lamZSM-5-(30)-BC140. The removal of the extraframework Al also explains the increase in the Si/Al ratio of the ZSM-5 (30)-AC13 (Si/Al=36), in comparison with the parent sample ( $\mathrm{Si} / \mathrm{Al}=30)$; the difference corresponds to the share of extraframework Al in the parent sample. Apparently, the harsh etching of as-synthesized layered ZSM-5 somehow provides a more resistant material towards dealumination during calcination, while the surfactant addition has the opposite effect (under the same conditions).

The relationship between the fluoride treatment and the concentration and strength of acid sites is more complex. All samples contain both Lewis and Brønsted acid sites. Fluoride etching after calcination (and the resulting absence of extra-framework Al) brings higher relative strengths of the acid sites. The lamZSM-5-(30)-AC13 sample contained approximately $33 \%$ of acid sites releasing pyridine at $350^{\circ} \mathrm{C}$

(Table 3), while in the parent material, $45 \%$ of acid sites were of the weaker character; however, similar strength (35\% loss) was also observed in the mildly etched as-synthesized sample (lamZSM-5-(30)-BC30) but not in the sample subjected to harsh treatment. The addition of a CTAB surfactant into the etching medium increased the concentration of Lewis acid sites proportionally to the difference in the amount of extra-framework Al (Table 3). Differences in the strength of the acid sites in the set of lamZSM-5-(35) samples were smaller (34-37\% of acid sites releasing pyridine at $350^{\circ} \mathrm{C}$ in all three catalysts), and the concentration of acid sites matched well the Si/Al ratio of each particular sample, which also shows the stability of the crystalline layers during etching. Therefore, we conclude that fluoride etching itself does not strongly affect the aluminium content and the acidic properties of layered ZSM-5 (like conventional 
ZSM-5). Instead, the observed alternations are caused by other sample treatments, particularly dealumination during calcination.

To further investigate the effect of fluoride etching on layered ZSM-5 catalysts, we performed two acidcatalysed test reactions: meta-xylene ( $\mathrm{m}-\mathrm{X})$ isomerisation and 1,3,5-tri-iso-propylbenzene (TiPBz) dealkylation. The $\mathrm{m}-\mathrm{X}$ isomerization gives us information on all the active sites of the catalyst, while TiPBz dealkylation exclusively occurs on the external surface of the catalyst. Figure 9 presents $\mathrm{m}-\mathrm{X}$ conversion as a function of catalyst loading (weight hour space velocity, WHSV) over the lamZSM-5-(35) and over its pillared and de-pillared form. The most active is the pillared catalyst, although its Si/Al ratio equal to 63 is a half of that of the layered ZSM-5 (35) (Si/Al=33). The improved accessibility of the active sites fully compensates their lower concentration. Conversely, the de-pillared catalyst has $\mathrm{Si} / \mathrm{Al}=53$, thus approximately $2 / 3$ of the parent catalyst, and morphology and textural properties are also similar to those of the parent zeolite. Consequently, conversion provided by de-pillared catalyst is approximately $2 / 3$ of that provided by the parent lamZSM-5-(35).

The differences in the performance of the etched layered ZSM-5 (30) catalysts (Figure 10) are less evident because their textural and acidic properties are closer to each other. Following the above scheme observed for the lamZSM-5-(35) derived catalysts, we can rationalise that the lamZSM-(30)BC140-CTAB catalyst provided the highest conversion and lamZSM-5-(30)-AC13 the lowest because of their Al content ( $\mathrm{Si} / \mathrm{Al}=25$ resp. 36). In other words, the number of the active sites is the main activity determinant. The remaining catalyst (laying in between) has a similar Al content and therefore other effects, such as differences in textural properties of the catalyst and in acidity strength and local environment of its active sites may account for the differences in the observed conversions.

In order to distinguish the effects of textural and acidic properties, the turnover frequency (TOF) per average Brønsted site (that is, considering all Brønsted active sites, quantified by pyridine desorption at 
$150^{\circ} \mathrm{C}$ ) were calculated (Figure 11). This TOF varied as a function of the BET area, while the catalysts were separated into two groups; parent catalysts (empty points) and etched catalysts (solid points). Importantly, the pill-ZSM-5-(35) catalyst (BET=606 $\mathrm{m}^{2} / \mathrm{g}$ ) fits between the etched catalysts, although it should fall in the parent group, because its acidic zeolite phase is diluted with silica pillars. The Figure 11 shows that the fluoride etching opens the structure, thereby increasing the BET area.

Both conversion and reaction selectivity are key properties. In $\mathrm{m}-\mathrm{X}$ isomerisation, para-xylene $(\mathrm{p}-\mathrm{X})$ is most often the desired product. Figure 12 presents $p-X$ selectivity data at $30 \% \mathrm{~m}-\mathrm{X}$ conversion for the discussed catalysts as a function of micropore volume (data obtained by linear interpolation of the selectivity curves Figure S 3, Figure S 4, supplementary information). From the thermodynamic equilibrium, $p-X$ selectivity (expressed as yield $(p-X)$ /conversion $(m-X)$ ) should be approx. 50\% (assuming equilibrium mixture o-X:m-X : p-X 25:50:25), while the observed values range from 61 to $67 \%$. Remaining part of products was o-xylene. Selectivity to other products such as toluene and 1,2,4trimethylbenzene was always $<1 \%$ at WHSV $=7.7$ and they were not detected at higher WHSV. The preference for $\mathrm{p}-\mathrm{X}$ results from the shape selectivity effect of the micropores on the catalyst, while the active sites on the external surface should decrease the selectivity. Thus, the higher the micropore volume is, the higher the selectivity will be. However, an inverted u-shaped curve with a maximum at $\mathrm{V}_{\text {mic }}=0.12 \mathrm{~cm}^{3} / \mathrm{g}$ is observed (the inverted parabolic function is explained in Figure $\mathrm{S} 5$, supplementary information, were additional points for several other layered ZSM-5 catalysts are added). The observed selectivity results from a complex relationship between catalyst micropore volume, external surface and transport properties. Therefore, catalyst morphology characterised by the aforementioned micropore volume $\left(V_{\text {mic }}=0.12 \mathrm{~cm}^{3} / g\right)$ likely accounts for the highest $p-X$ selectivity of $66.7 \%$ at $30 \% \mathrm{~m}-\mathrm{X}$ conversion. TiPBz is a highly sterically demanding molecule (kinetic diameter $0.95 \mathrm{~nm}$ ) [16] unable to penetrate the micropores of any zeolite. Therefore, TiPBz dealkylation provides information about acid sites located on 
the external surface and in mesopores, accessible from the external surface. Figure 13 shows TiPBz conversions over the lamZSM-5-(30)-based catalysts as a function of the number of strong acid sites (binding pyridine after desorption at $350^{\circ} \mathrm{C}$ ). 1,3-diisopropylbenzene is the main product in all cases (selectivity $60-79 \%$ depending on conversion) but the key information is provided by the bulky TiPBz conversion since 1,3-diisopropylbenzene is the only primary product. These catalysts can be sorted into two groups: the group of the more active catalysts includes the parent lamZSM-5-(30) and the lamZSM5-(30)-AC13 (conversion $8 \%$ resp. 9\% in 2 min T-O-S), while the remaining three catalysts, etched before calcination, are less active (conversion 3-6\% in 2 min T-O-S). The comparison of the former two catalysts meets the expectations: higher concentration of strong acid sites and higher external surface provide higher TiPBz conversion (concentration of external surface Brønsted acid sites analysed by collidine adsorption: $C_{B}\left(\right.$ lamZSM-5-(30)) $=0.049 \mathrm{mmol} / \mathrm{g}$ vs. $\mathrm{C}_{B}($ lamZSM-5-(30)-AC13) $=0.060 \mathrm{mmol} / \mathrm{g})$. However, the interpretation of the results of the other three catalysts is complex. For example, the correlation between higher external surface area (and higher concentration of external surface acid sites), providing higher conversion, does not apply in this group of catalysts. Presumably, these differences are explained by the changes caused by fluoride etching. However, this interpretation cannot be extracted from the present characterisation data set. Furthermore, the location of the acid sites that actually participate in the TiPBz dealkylation reaction when a ZSM-5 nanosheet of only 1.5 unit cell thickness (i.e., two rows of zig-zag channels) acts as catalyst remains unknown.

\section{Conclusions}

Fluoride etching of 2-dimensional forms of ZSM-5 zeolite was investigated in the present paper. Concentrated ammonium fluoride solutions are known to remove both framework cations (Si and Al) from zeolites, starting from lattice defects. The etching of layered ZSM-5, particularly in forms without a template (layered calcined and pillared), was expected to be fast and difficult to control; however, the 2dimensional ZSM-5 was unexpectedly stable under etching conditions. Although the layered ZSM-5 has 
discrete single crystals of one or few unit cell thickness, the part of this zeolite that dissolved was the same as that of the conventional ZSM-5, under the same conditions. In contrast to conventional ZSM-5 crystals, the presence of misoriented crystalline domains, which would be preferentially extracted, was negligible. We attribute this fact to the particular growth mechanism, which is promoted by the surfactant template in layered ZSM- 5 . Otherwise, the dissolution of layered ZSM- 5 is fairly similar to that of conventional micro-sized ZSM-5 crystals. For instance, the etching started by dissolution of amorphous and extra-framework species, which resulted in the complete removal of extra-framework Al in calcined layered ZSM-5 and in the de-pillaring of pillared ZSM-5. The resulting de-pillared ZSM-5 had morphology and textural properties very similar to the parent layered ZSM-5. Therefore, the zeolite itself remained almost unchanged. Only the interlayer $d$-spacing decreased with the removal of silica pillars. TEM images of the etched (both as-synthesized and calcined) materials revealed a flake-like morphology combining features of layered and nanocrystalline ZSM-5, while the materials preserved their macroscopic features.

Fluoride etching combined with framework dealumination during calcination changed the concentration and strength of the acid sites, whose effects, together with changes in textural properties, were observed in acid catalysed $m$-xylene isomerisation and 1,3,5-triisopropylbenzene de-alkylation reactions. The inverted u-shaped curve of the function of para- selectivity in $m$-xylene isomerisation with catalyst micropore volume peaks at $0.12 \mathrm{~cm}^{3} / \mathrm{g}$ (evaluated at $30 \%$ conversion). TiPBz conversion depends on the concentration of strong acid sites (withstanding pyridine desorption at $350^{\circ} \mathrm{C}$ ) and on the form in which the layered ZSM-5 is etched (as-synthesized vs. calcined). The parent layered ZSM-5 (30) and lamZSM-5(30)-AC13, which was etched after template removal (calcination), provided a significantly higher conversion than samples etched before template removal. 
To our best knowledge, this is the first study of the fluoride etching of a 2-dimensional zeolite, which lays the foundation for deeper and more advanced studies in the future.

\section{Acknowledgment}

The authors acknowledge the financial support of the ANR project DirectSynBuoFuel (No. 15-CE06-

0004). J.P. thanks to language editor Dr. Carlos Henrique Vieira Melo.

\section{References}

[1] J. Čejka, R.E. Morris, P. Nachtigall (Eds.), Zeolites in Catalysis. Properties and Applications, Royal Society of Chemistry, Cambridge, 2017.

[2] K.F. Kalz, R. Kraehnert, M. Dvoyashkin, R. Dittmeyer, R. Gläser, U. Krewer, K. Reuter, J.-D. Grunwaldt, ChemCatChem, 9 (2017) 17-29, https://doi.org /10.1002/cctc.201600996

[3] V. Valtchev, L. Tosheva, Chem. Rev., 113 (2013) 6734-6760, https://doi.org /10.1021/cr300439k

[4] S. Mintova, J. Grand, V. Valtchev, Comptes Rendus Chimie, 19 (2016) 183-191, https://doi.org/10.1016/j.crci.2015.11.005

[5] J. Perez-Ramirez, C.H. Christensen, K. Egeblad, C.H. Christensen, J.C. Groen, Chem. Soc. Rev., 37 (2008) 2530-2542, https://doi.org/10.1039/b809030k

[6] W.J. Roth, P. Nachtigall, R.E. Morris, J. Čejka, Chem. Rev., 114 (2014) 4807-4837, https://doi.org/10.1021/cr400600f

[7] W.J. Roth, C.T. Kresge, J.C. Vartuli, M.E. Leonowicz, A.S. Fung, S.B. McCullen, Stud. Surf. Sci. Catal., 94 (1995) 301-308, https://doi.org/10.1016/S0167-2991(06)81236-X

[8] P. Wu, J.F. Ruan, L.L. Wang, L.L. Wu, Y. Wang, Y.M. Liu, W.B. Fan, M.Y. He, O. Terasaki, T. Tatsumi, J. Am. Chem. Soc., 130 (2008) 8178-8187, https://doi.org /10.1021/ja0758739

[9] F.S. Xiao, B. Xie, H.Y. Zhang, L. Wang, X.J. Meng, W.P. Zhang, X.H. Bao, B. Yilmaz, U. Muller, H. Gies, H. Imai, T. Tatsumi, D. De Vos, ChemCatChem, 3 (2011) 1442-1446, https://doi.org/10.1002/cctc.201100144

[10] A. Corma, V. Fornes, S.B. Pergher, T.L.M. Maesen, J.G. Buglass, Nature, 396 (1998) 353-356, https://doi.org /10.1038/24592

[11] W.J. Roth, Stud. Surf. Sci. Catal., 158A and B (2005) 19-26, https://doi.org/10.1016/S01672991(05)80317-9 
[12] M. Mazur, V. Kasneryk, J. Přech, F. Brivio, C. Ochoa-Hernández, A. Mayoral, M. Kubů, J. Čejka, Inorganic Chemistry Frontiers, (2018), https://doi.org /10.1039/C8QI00732B

[13] P. Eliášová, M. Opanasenko, P.S. Wheatley, M. Shamzhy, M. Mazur, P. Nachtigall, W.J. Roth, R.E. Morris, J. Čejka, Chem. Soc. Rev., 44 (2015) 7177-7206, https://doi.org/10.1039/C5CS00045A

[14] M. Choi, K. Na, J. Kim, Y. Sakamoto, O. Terasaki, R. Ryoo, Nature, 461 (2009) 828-828, https://doi.org/10.1038/nature08288

[15] Z. Qin, L. Lakiss, J.P. Gilson, K. Thomas, J.M. Goupil, C. Fernandez, V. Valtchev, Chem. Mater., 25 (2013) 2759-2766, https://doi.org /10.1021/cm400719z

[16] Z. Qin, G. Melinte, J.-P. Gilson, M. Jaber, K. Bozhilov, P. Boullay, S. Mintova, O. Ersen, V. Valtchev, Angew. Chem. Int. Ed., 55 (2016) 15049-15052, https://doi.org /10.1002/anie.201608417

[17] L. Brabec, M. Kočiřík, Materials Chemistry and Physics, 102 (2007) 67-74, https://doi.org/10.1016/j.matchemphys.2006.11.007

[18] B.C. Lippens, J.H. de Boer, J. Catal., 4 (1965) 319-323, https://doi.org /10.1016/00219517(65)90307-6

[19] F. Ngoye, L. Lakiss, Z. Qin, S. Laforge, C. Canaff, M. Tarighi, V. Valtchev, K. Thomas, A. Vicente, J.P. Gilson, Y. Pouilloux, C. Fernandez, L. Pinard, J. Catal., 320 (2014) 118-126, https://doi.org/10.1016/j.jcat.2014.10.001

[20] J. Fermoso, H. Hernando, P. Jana, I. Moreno, J. Přech, C. Ochoa-Hernández, P. Pizarro, J.M. Coronado, J. Čejka, D.P. Serrano, Catal. Today, 277 (2016) 171-181, https://doi.org/10.1016/j.cattod.2015.12.009

[21] A. Peral, J.M. Escola, D.P. Serrano, J. Přech, C. Ochoa-Hernández, J. Čejka, Catal. Sci. Technol., 6 (2016) 2754-2765, https://doi.org /10.1039/C5CY02075A

[22] W. Park, D. Yu, K. Na, K.E. Jelfs, B. Slater, Y. Sakamoto, R. Ryoo, Chem. Mater., 23 (2011) 5131-5137, https://doi.org/10.1021/cm201709q

[23] K. Na, M. Choi, W. Park, Y. Sakamoto, O. Terasaki, R. Ryoo, J. Am. Chem. Soc., 132 (2010) 41694177, https://doi.org/10.1021/ja908382n

[24] R.J. Messinger, K. Na, Y. Seo, R. Ryoo, B.F. Chmelka, Angew. Chem. Int. Ed., 54 (2015) 927-931, https://doi.org/10.1002/anie.201408623

[25] J. Přech, P. Eliášová, D. Aldhayan, M. Kubů, Catal. Today, 243 (2015) 134-140, http://doi.org/10.1016/j.cattod.2014.07.002

[26] A.G. Machoke, I.Y. Knoke, S. Lopez-Orozco, M. Schmiele, T. Selvam, V.R.R. Marthala, E. Spiecker, T. Unruh, M. Hartmann, W. Schwieger, Microporous Mesoporous Mater., 190 (2014) 324-333, https://doi.org/10.1016/j.micromeso.2014.02.026 
[27] C.A. Fyfe, G.C. Gobbi, J.S. Hartman, J. Klinowski, J.M. Thomas, J. Phys. Chem., 86 (1982) 1247-1250, https://doi.org/10.1021/j100397a006

[28] G. Majano, L. Delmotte, V. Valtchev, S. Mintova, Chem. Mater., 21 (2009) 4184-4191, https://doi.org/10.1021/cm900462u

[29] Y. Tao, H. Kanoh, L. Abrams, K. Kaneko, Chem. Rev., 106 (2006) 896-910, https://doi.org/10.1021/cr040204o

[30] R. Szostak, in: H. van Bekkum, E.M. Flanigen, P.A. Jacobs, J.C. Jansen (Eds.) Stud. Surf. Sci. Catal. 137, Elsevier, Amsterdam, 2001, pp. 261-297. 
Table 1: Fluoride etching conditions for the series of studied samples

\begin{tabular}{lccc}
\hline Sample & $\begin{array}{c}\mathbf{w}\left(\mathbf{N H}_{\mathbf{4}} \mathrm{F}\right) \\
(\mathbf{w t .} \%)\end{array}$ & $\begin{array}{c}\text { temp. } \\
\left({ }^{\circ} \mathbf{C}\right)\end{array}$ & $\begin{array}{c}\text { time } \\
(\mathbf{m i n})\end{array}$ \\
\hline lamZSM-5-(30) & -- & -- & -- \\
lamZSM-5-(30)-BC30 & 20 & 50 & 30 \\
lamZSM-5-(30)-BC140 & 40 & 50 & 140 \\
lamZSM-5-(30)-BC140-CTAB ${ }^{\text {a }}$ & 40 & 50 & 140 \\
lamZSM-5-(30)-AC5 & 20 & 33 & 5 \\
lamZSM-5-(30)-AC13 & 40 & 40 & 13 \\
\hline lamZSM-5-(35) & -- & -- & -- \\
pill-ZSM-5-(35) & -- & -- & -- \\
de-pill-ZSM-5-(35) & 40 & 50 & 10 \\
\hline
\end{tabular}

a 10 wt.\% of CTABr added to the etching solution 
Table 2: Textural properties of parent and etched samples

\begin{tabular}{lcccc}
\hline Sample & $\begin{array}{c}\mathbf{B E T} \\
\left(\mathbf{m}^{2} / \mathbf{g}\right)\end{array}$ & $\begin{array}{c}\mathbf{V}_{\text {mic }} \\
\left(\mathbf{c m}^{3} / \mathbf{g}\right)\end{array}$ & $\begin{array}{c}\mathbf{V}_{\text {tot }} \\
\left(\mathbf{c m}^{\mathbf{3}} / \mathbf{g}\right)\end{array}$ & $\begin{array}{c}\mathbf{S}_{\text {ext }} \\
\left(\mathbf{m}^{2} / \mathbf{g}\right)\end{array}$ \\
\hline lamZSM-5-(30) & 393 & 0.135 & 0.315 & 86 \\
lamZSM-5-(30)-BC30 & 403 & 0.129 & 0.302 & 92 \\
lamZSM-5-(30)-BC140 & 472 & 0.135 & 0.388 & 142 \\
lamZSM-5-(30)-BC140-CTAB & 458 & 0.128 & 0.414 & 160 \\
lamZSM-5-(30)-AC5 & 438 & 0.134 & 0.323 & 106 \\
lamZSM-5-(30)-AC13 & 430 & 0.138 & 0.333 & 108 \\
\hline lamZSM-5-(35) & 364 & 0.122 & 0.391 & 96 \\
pill-ZSM-5-(35) & 606 & 0.103 & 0.53 & 86 \\
de-pill-ZSM-5-(35) & 429 & 0.139 & 0.278 & 74 \\
\hline
\end{tabular}


Table 3: Aluminum content, concentration of acid sites and number of extra-framework Al species in the parents and etched derivatives

\begin{tabular}{|c|c|c|c|c|c|c|c|c|}
\hline Sample & $\mathrm{Si} / \mathrm{Al}^{\mathrm{a}}$ & $\begin{array}{l}\mathrm{c}(\mathrm{L} 150)^{\mathrm{b}} \\
\mathrm{mmol} / \mathrm{g}\end{array}$ & $\begin{array}{l}\mathrm{c}(\mathrm{B} 150)^{\mathrm{b}} \\
\mathrm{mmol} / \mathrm{g}\end{array}$ & $\begin{array}{l}\mathrm{c}(\mathrm{L} 350)^{\mathrm{c}} \\
\mathrm{mmol} / \mathrm{g}\end{array}$ & $\begin{array}{l}\mathrm{c}(\mathrm{B} 350)^{\mathrm{c}} \\
\mathrm{mmol} / \mathrm{g}\end{array}$ & $\begin{array}{c}\text { loss (150- } \\
350) \%^{d}\end{array}$ & $\begin{array}{l}\text { extra } \\
\mathrm{Al}^{\mathrm{e}} \%\end{array}$ & $\mathrm{Al}^{3+} \%{ }^{\mathrm{e}}$ \\
\hline lamZSM-5-(30) & 30 & 0.134 & 0.116 & 0.079 & 0.059 & $45 \%$ & $16.5 \%$ & $1.9 \%$ \\
\hline lamZSM-5-(30)-BC30 & 29 & 0.135 & 0.192 & 0.113 & 0.099 & $35 \%$ & $16.0 \%$ & $4.2 \%$ \\
\hline lamZSM-5-(30)-BC140 & 31 & 0.112 & 0.116 & 0.075 & 0.059 & $41 \%$ & $6.5 \%$ & $4.8 \%$ \\
\hline lamZSM-5-(30)-BC140-CTAB & 25 & 0.172 & 0.133 & 0.091 & 0.081 & $44 \%$ & $18.0 \%$ & $3.4 \%$ \\
\hline lamZSM-5-(30)-AC13 & 36 & 0.123 & 0.162 & 0.092 & 0.098 & $33 \%$ & $0.0 \%$ & $0.0 \%$ \\
\hline lamZSM-5-(35) & 33 & 0.121 & 0.184 & 0.096 & 0.097 & $37 \%$ & n.d. & n.d. \\
\hline pill-ZSM-5-(35) & 63 & 0.111 & 0.065 & 0.078 & 0.035 & $36 \%$ & n.d. & n.d. \\
\hline de-pill-ZSM-5-(35) & 53 & 0.096 & 0.11 & 0.066 & 0.069 & $34 \%$ & n.d. & n.d. \\
\hline
\end{tabular}

${ }^{\mathrm{a}} \mathrm{Si} / \mathrm{Al}$ molar ratio by ICP-OES; ${ }^{\mathrm{b}}$ concentration of Lewis (L150) and Brønsted (B150) acid sites measured after pyridine desorption at $150^{\circ} \mathrm{C} ;{ }^{\mathrm{c}}$ concentration of Lewis (L350) and Brønsted (B350) acid sites measured after pyridine desorption at $350^{\circ} \mathrm{C} ;{ }^{\mathrm{d}}$ share of acid sites (Lewis+Brønsted) which is not strong enough to bind pyridine at $350^{\circ} \mathrm{C}$; ${ }^{\mathrm{e}}$ share of total extra-framework aluminum and octahedral cationic aluminium determined by ${ }^{27}$ Al-MAS-NMR; n.d. means not determined. 


\section{Figure captions}

Figure 1: SEM images of lamZSM-5-(30) (a), lamZSM-5-(30)-BC30 (b), lamZSM-5-(30)-BC140 (c), lamZSM5-(30)-BC140-CTAB (d), lamZSM-5-(30)-AC5 (e), lamZSM-5-(30)-AC13 (f)

Figure 2: XRD patterns of the parent layered ZSM-5 (30) before and after calcination and related etched samples

Figure 3: Low- (left) and high-angle (right) XRD pattern of the layered, pillared and de-pillared ZSM-5 (35); the XRD pattern for lamZSM-5-(35) was measured using a Bruker AXS D8 Advance diffractometer equipped with a position sensitive detector Våntec-1 and a beam-knife using CuKa radiation

Figure 4: Nitrogen sorption isotherms for lamZSM-5-(35) (black circles), pill-ZSM-5-(35) (black diamonds) and de-pill-ZSM-5-(35) (grey circles); empty points denote desorption

Figure 5: Low (left) and high (right) magnification SEM images of lamZSM-5-(35) (top), pill-ZSM-5-(35) (middle), de-pillared ZSM-5 (35) (bottom)

Figure 6: High resolution TEM images of lamZSM-5-(30) (a), lamZSM-5-(30)-BC30 (b), lamZSM-5-(30)BC140-CTAB (c), lamZSM-5-(30)-AC13 (d) revealing the $10 \AA$ periodicity in all the samples

Figure 7: TEM images of lamZSM-5-(30) (a), lamZSM-5-(30)-BC30 (b), lamZSM-5-(30)-BC140-CTAB (c), lamZSM-5-(30)-AC13 (d)

Figure 8: ${ }^{27} \mathrm{Al}-\mathrm{MAS}-\mathrm{NMR}$ spectra of lamZSM-5-(30) (bottom) and derived samples

Figure 9: m-xylene conversion over layered, pillared and de-pillared ZSM-5 (35) at $350^{\circ} \mathrm{C}$ and $101 \mathrm{kPa}$

Figure 10: $\mathrm{m}$-xylene conversion as function of WHSV at $350^{\circ} \mathrm{C}$ and $101 \mathrm{kPa}$ over the catalysts of lamZSM$5-(30)$ series

Figure 11: TOF per average Brønsted acid site as function of BET area of the catalyst. TOF was calculated at WHSV=7.8; empty diamonds: parent samples; full diamonds: fluoride etched samples; empty circle: pillared ZSM-5

Figure 12: $p$-xylene selectivity at $30 \%$ conversion of $m$-xylene vs. micropore volume of the catalyst at $350^{\circ} \mathrm{C}$ and $101 \mathrm{kPa}$

Figure 13: TiPBz conversion vs. concentration of strong acid sites over lamZSM-5-(30) series catalysts after 2 min time-on-stream at $220^{\circ} \mathrm{C}$ and $101 \mathrm{kPa}$ 


\section{Highlights}

- layered ZSM-5 was etched using concentrated $\mathrm{NH}_{4} \mathrm{~F}$ solutions

- layered ZSM-5 is unexpectedly stable under etching conditions

- fluoride etching opens the structure of layered ZSM-5 increasing the external surface

- pillared ZSM-5 was de-pillared by removing the amorphous silica pillars

- removal of extra-framework Al strengthens the active sites 
a

b

$2 \mu \mathrm{m}$

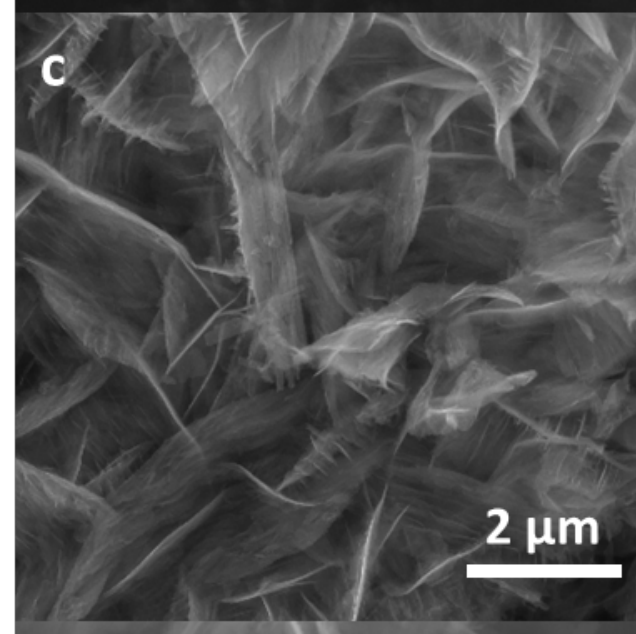

d

e

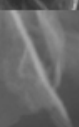




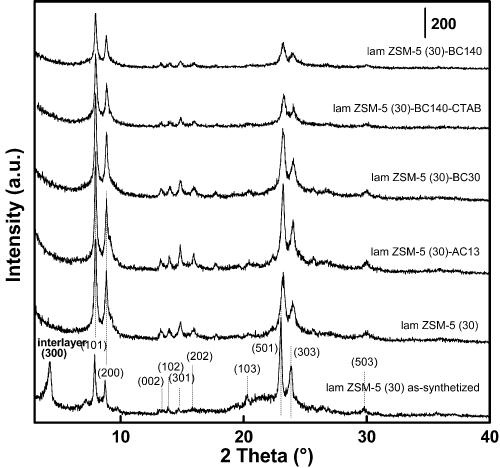




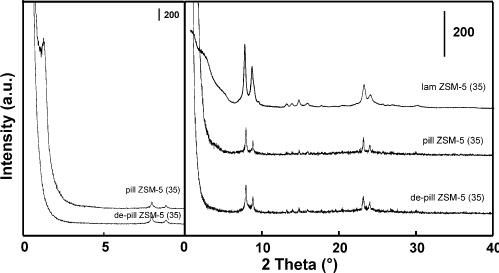




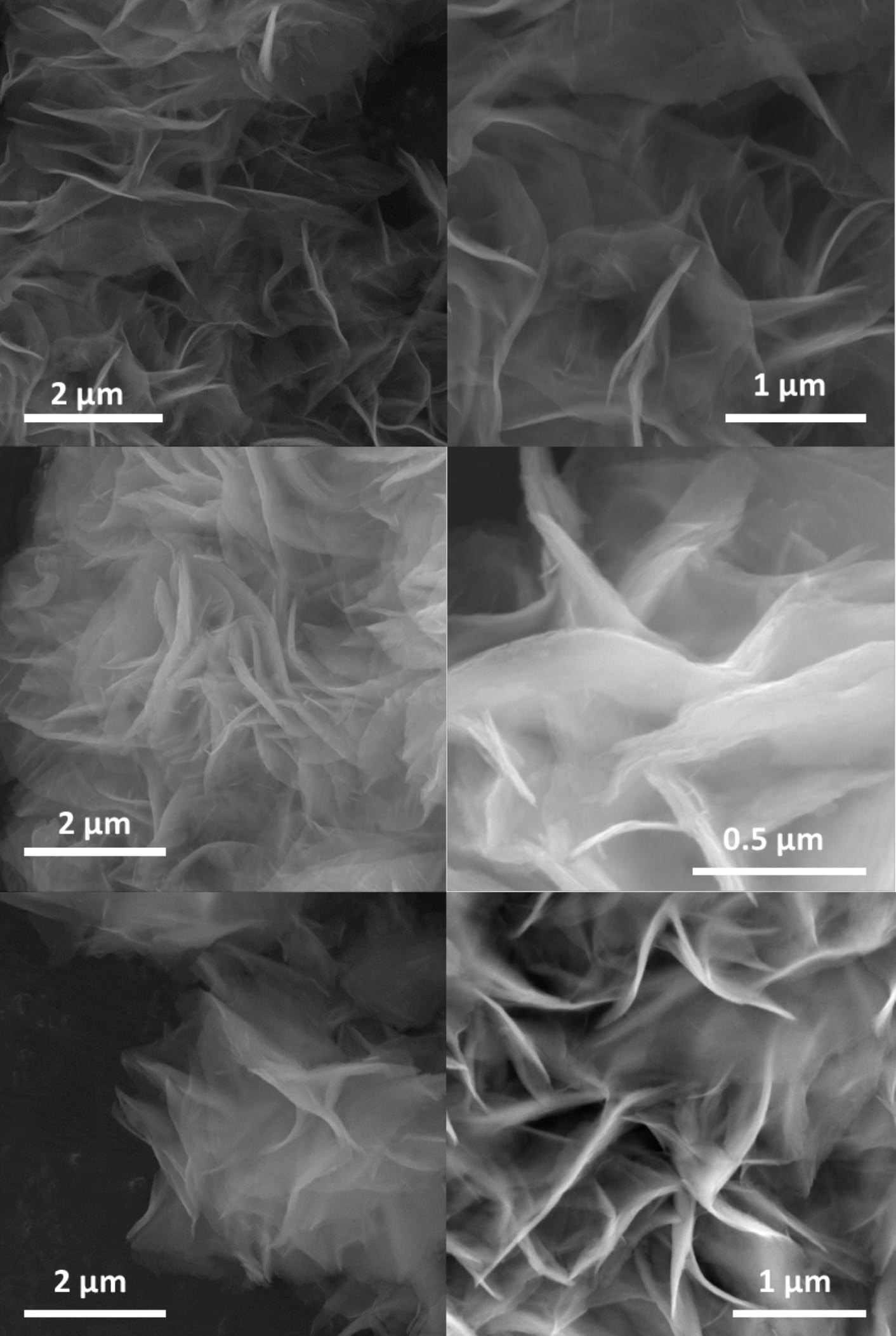




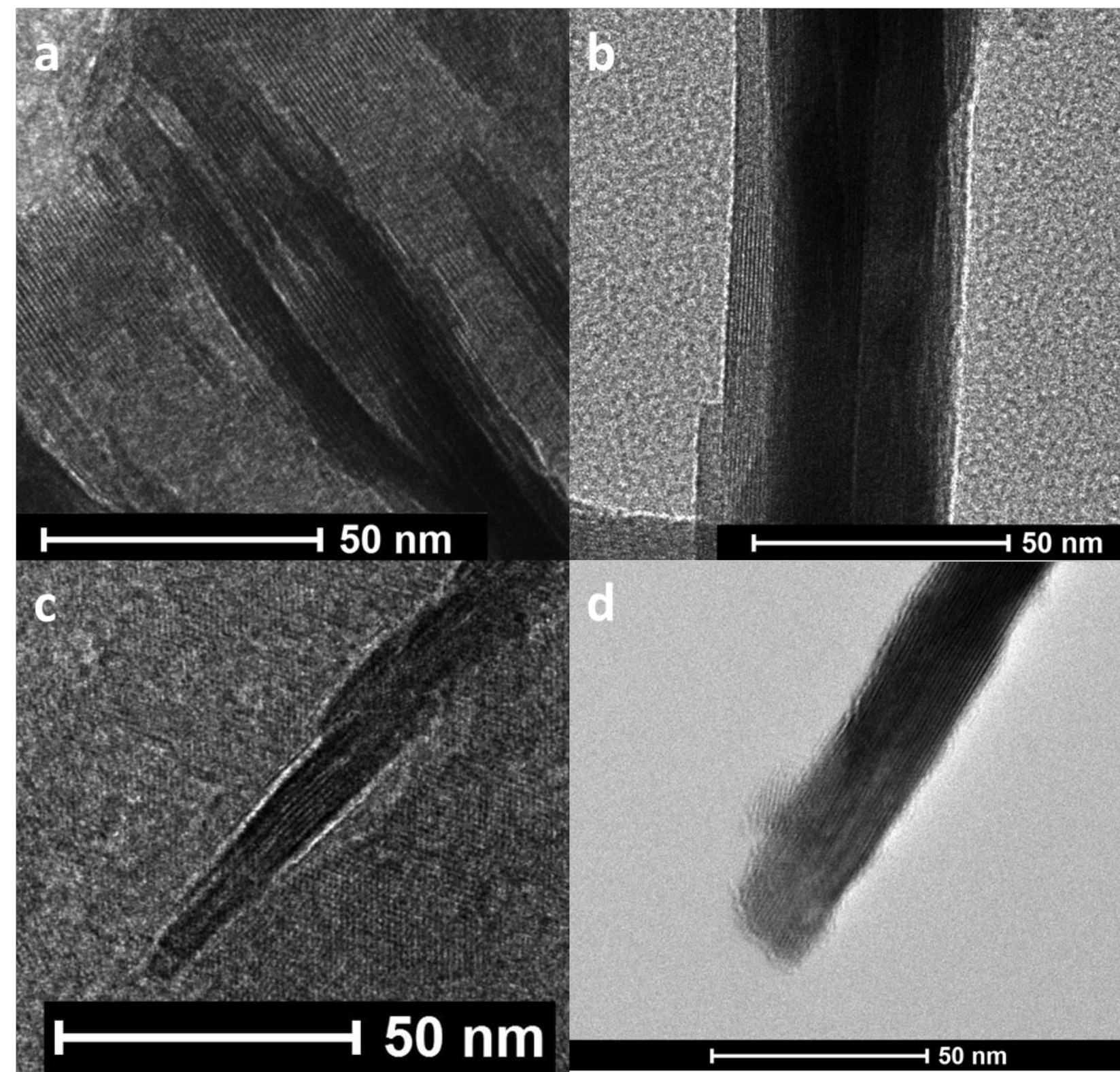




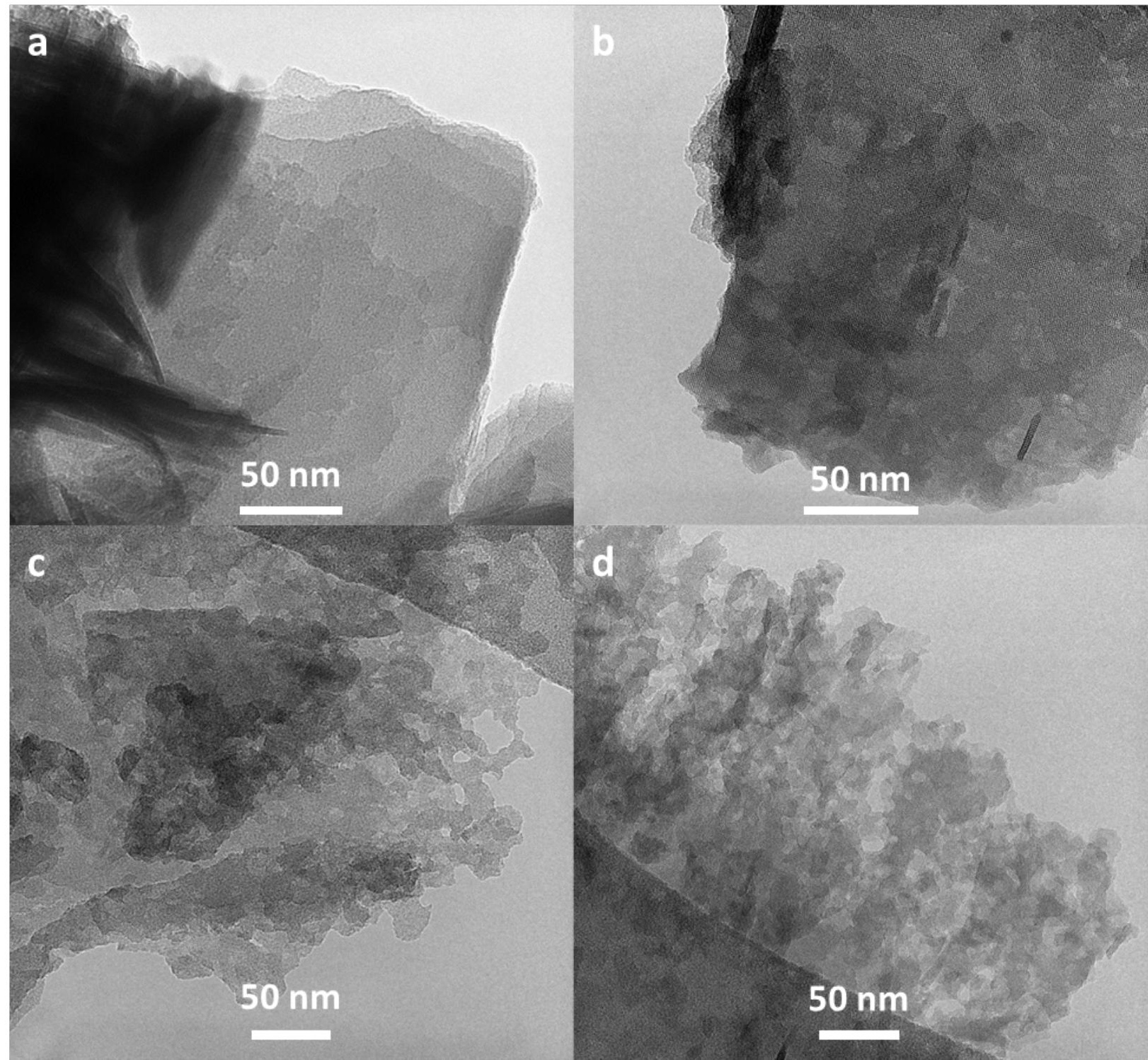




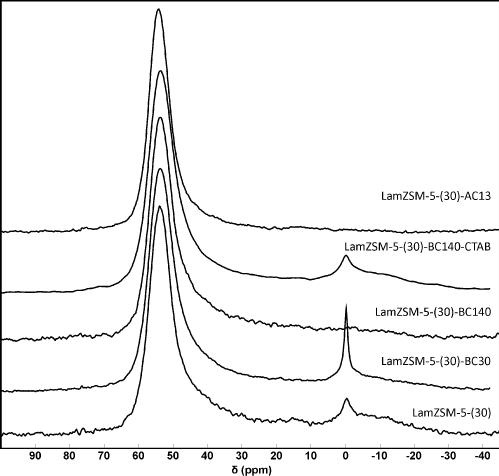




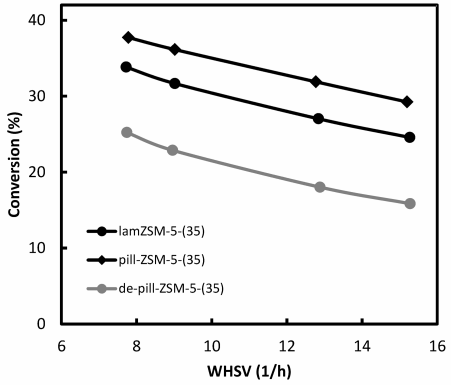




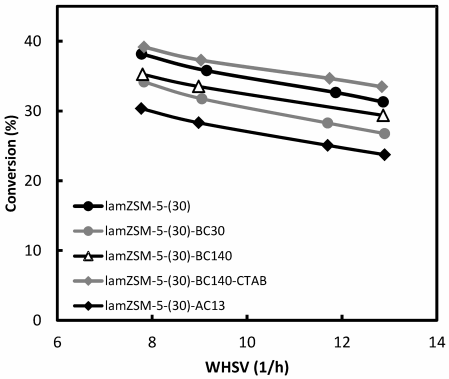




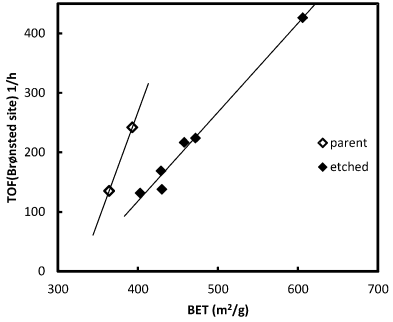




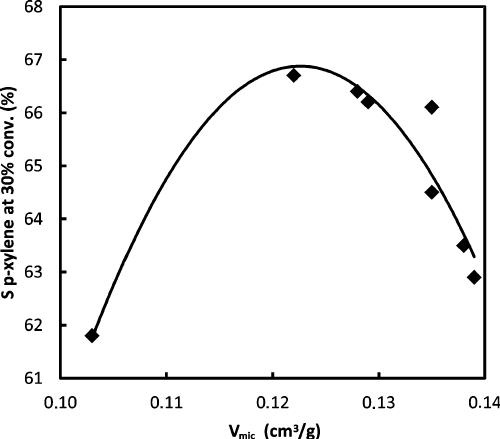




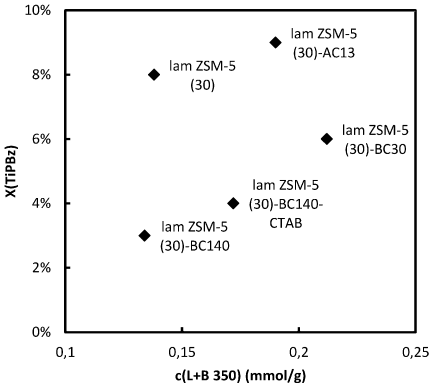


109090900903 ro9090090909 2000009000909 6000 dododo

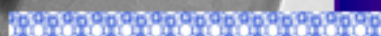 \\ $\mathrm{NH}_{4} \mathrm{~F}$

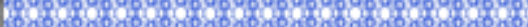

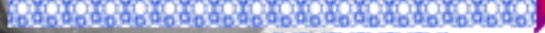
10.0808088980

$10009090 \%$

800250000000000 1000000000000

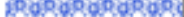

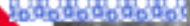
1090000090009090909090903

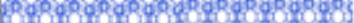
$50 \mathrm{~nm}$ 